\title{
Diet and Health
}

\author{
JAMES M. HUNDLEY, M.D.
}

$\mathbf{R}$ ISING LEVELS of health have been a prominent feature of the American scene over many decades. Declining mortality, increased longevity, lower infant and maternal mortality rates, total eradication of some infectious diseases such as yellow fever, malaria, and smallpox, and effective control of others such as pneumonia, influenza, tuberculosis, and poliomyelitis are concrete manifestations of progress.

Many factors have accounted for this-better medical care, better sanitation, improved methods of disease prevention, rising levels of education and income, better diets, and improved levels of nutrition. Nutritional deficiency diseases such as pellagra and scurvy have virtually disappeared. Children are growing more rapidly than ever before. Adults are taller and heavier.

True, we still have "pockets of malnutrition" in certain socioeconomic groups. Undoubtedly diets could be further improved for some segments of the population. However, malnutrition still persisting is due largely to poverty, ignorance, misguided dieting, or food faddism, or is secondary to other causes such as alcoholism. Certainly an abundance of good nutritious food is available.

Milk and other dairy products make a unique contribution to the adequacy of our diets. Milk is unrivaled in nutritive value, palatability, digestibility, and versatility. Its consumption

Dr. Hundley is an Assistant Surgeon General in the Public Health Service. This paper was presented to the National Conference on Milk and Nutrition sponsored by the U.S. Department of Agriculture, January 23, 1962, Washington, D.C. is firmly rooted in American culture as a main pillar of nutritional adequacy. Much of the general improvement in our diets over the last decades can be attributed to increasing consumption of milk and other dairy products.

As older health problems have come under control, new problems have arisen in their place. Accidents and cancer are now the leading causes of death in children under 15 years of age. A large segment of adults, perhaps 10 to 20 percent, are overnourished, that is, obese. Our senior citizens have special health problems. Cardiovascular diseases, especially coronary heart disease, and cancer are now the leading causes of death and disability.

There are some indications that health progress has reached a plateau in this country. The general death rate has changed very little since 1956. Several countries now appear to have a better record of infant mortality than we do. Many countries have less heart disease. In any event, it is clear that if further substantial health progress is to be achieved we must find ways to control cardiovascular diseases and cancer. Much progress has already been achieved in some aspects but nothing like a real breakthrough has yet come. There is some evidence that a breakthrough may be achieved through diet. Naturally, such a possibility is generating great interest and a tremendous amount of research.

\section{Diet and Heart Disease}

Evidence has accumulated over many years suggesting that cholesterol, a fatty substance present in blood and in certain foods, is somehow related to coronary heart disease. A few 
years ago it was thought that diets low in cholesterol might lower blood cholesterol and hence reduce the risk of coronary artery disease. We now know that levels of blood cholesterol are relatively independent of dietary cholesterol.

More recently it has been found that the type and amount of fat in the diet does have important effects. Saturated fats tend to increase blood cholesterol, whereas unsaturated fats lower it. From this and much additional evidence, a theory has been derived that diets high in saturated fats increase blood cholesterol, and the increased cholesterol level favors the development of atherosclerosis, which leads to coronary artery disease. This possibility has tremendous implications for the dairy industry, since the fat of milk is of the saturated type. Drastic alterations in our pattern of consumption of dairy products would be required if this theory should be proved correct.

At this point I want to emphasize that this theory is not proved. Some links in the chain of evidence supporting the theory are quite solid. Others are weak or missing. Much of the evidence is indirect, that is, attempts to show guilt by association. Substantiation for the crucial part of the theory-that lowering dietary fat or increasing unsaturated fats will prevent coronary artery disease-is the real missing link. The final answer can come only from research in man himself, and it will take several years, perhaps 5 or 10 , to get it. Several studies designed to get the answer are underway, and others are in the planning stage.

In addition, it must be remembered that high blood cholesterol is only one of a number of factors which have been related to the incidence of coronary artery disease. Age and sex are factors. Men over 40 are more susceptible. Heredity plays a role, since the disease is more common in persons having parents or close relatives who have had the disease. Heavy smokers and those with high blood pressure are more likely to develop a coronary attack. Obesity seems to be a predisposing condition. Exercise may play a role. Certain diseases such as diabetes, hypothyroidism, and renal damage seem to be associated with increased susceptibility. In no instance has it been shown that any of these factors, including diet, play a causative role. It is evident that the situation is very complex. A number of factors, perhaps some not currently recognized, may ultimately be shown important in control of the disease.

At the moment it is entirely clear that the evidence relating diet to coronary disease is insufficient to justify recommending that the general public change its dietary patterns with respect to dairy products. To do so would be trading uncertain and unproved benefits for the certain and well-established benefits which dairy products bring to our diet.

I realize that some physicians are prescribing diets low in saturated fats for patients who have had a coronary attack or for those who are thought to be prone to develop coronary heart disease. This, however, is a matter for medical judgment on an individual patient basis. It does not justify comparable dietary practices by the general public, to whom much more damage than good might be done. Some knowledgeable physicians believe that all those falling in the so-called coronary-prone group, that is, those with more than one of the associated and predisposing factors discussed above, should also be on these special diets. They may be correct, but the case is not yet proved and should be a matter of medical judgment and individual prescription.

As the principal Federal agency broadly concerned with the nation's health, the Public Health Service is following the situation closely and is making every effort to get the true answers as rapidly as possible. If it should develop that dietary changes are justified, we would promptly advocate and promote such changes. We have not, however, made such recommendations. Watching one's weight, eating a variety of foods, being moderate in all things including the amount and types of food eaten, and exercising as regularly as possible are still sound rules to follow.

\section{Radioactive Fallout in Foods}

The public has also become concerned, and perhaps more than a little confused, about another relatively recent development with profound health implications. This is the radiation fallout problem which the recent Soviet nuclear tests have brought into acute focus. All foods, including milk, are involved since radio- 
active fallout products appear in all of them. Iodine 131 and strontium 90 are the radioactive products in milk which have received the most attention. Again there is reason to believe that there is a degree of concern out of proportion to the facts.

What are the facts?

First, it is well to remember that radiation has always been with us. Life on earth has developed to its present state amid continuous natural radiation from rocks, soil, and outer space. With the discovery and widespread use of radium, X-rays, and various radioisotopes, radiation exposure has increased. Fallout from nuclear explosions simply adds to what is already present.

Second, a great deal has been learned about the biological effects of exposure to radiation. While much more information is needed, present knowledge is sufficient to enable the Federal Radiation Council to develop guidelines to protect the health of the American people.

Third, the amount of radiation in milk, in food generally, in air, and in drinking water is under constant surveillance. The Public Health Service, in cooperation with State and local health departments, operates a nationwide "early warning" radiation surveillance network comprised of more than 60 stations for atmospheric sampling. There are also more than 60 stations for milk sampling and about 20 stations for total diet sampling. In addition, we have well-established networks for general air and water pollution monitoring with a total of 343 stations. The Food and Drug Administration works through 18 district offices and 39 resident inspection stations to sample foods from all parts of the nation. In addition, there are extensive special purpose radiation surveillance and research facilities of the Atomic Energy Commission, and the Departments of Defense, Commerce, and Agriculture. All Federal programs work in close coordination, and all follow the same radiation protection standards through the coordinating influence of the Federal Radiation Council.

Fourth, the amounts of radioactive material in food generally and in milk specifically are now and have been in the past well below the level at which any actions to reduce intake of radioactivity are indicated according to the
Federal Radiation Council's guidelines, which have been accepted by the President. There is no reason whatsoever for the public to reduce consumption of milk or other dairy products because of fear of radioactive contamination. The iodine 131 from the recent Soviet tests has already disappeared from milk. Even the peak levels of strontium 90 expected this spring will still be below levels which the Federal Radiation Council indicates would call for consideration of measures designed to reduce the levels in milk.

Fifth, with specific reference to milk, it is important to emphasize that the human body must have calcium.

There is evidence indicating that animals on good calcium intakes absorb less strontium, and conversely animals that are calcium-depleted absorb more strontium. Since milk and milk products supply about three-fourths of the calcium in our diets, the importance of this point is obvious.

Strontium 90 is important because it is deposited in bones. Experimental evidence at high levels indicates that it can induce bone cancers and perhaps leukemia. However, at levels which have occurred in the past and which we expect in the future, the risk to the total population of these effects is small and, to any individual, very small. As in many other fields of medicine and health, radiation control efforts are based upon balancing risk against benefit. The same must be said for that part of radiation control we are considering today. The presumed benefits of any particular countermeasure must be balanced carefully against the risks. What might be the health impact of any major disruption of an industry whose product is essential to the maintenance of adequate nutrition in this country, particularly among infants, children, and teenagers, who must have adequate calcium for their growing bone structures?

Progress has its price. Automobiles are a blessing and essential to our economy; yet they kill a lot of people. Atomic energy will ultimately bring great benefits to mankind; yet it has its hazards. If we had a complete choice we would say that desirable levels of radiation exposure were zero-none at all. But nature herself has dictated that this can never be. 
Consequently, we must balance risks against benefits. This is the price of progress.

The American public is very health conscious. It is eager for information on how to improve health and prevent disease. It wants to be informed. At times the public receives information which is still in the research stage or which is not readily understood in practical terms. At times the public reacts prematurely or unwisely. This too is a price for progress. With time and sound education, however, such situations resolve into proper perspective.

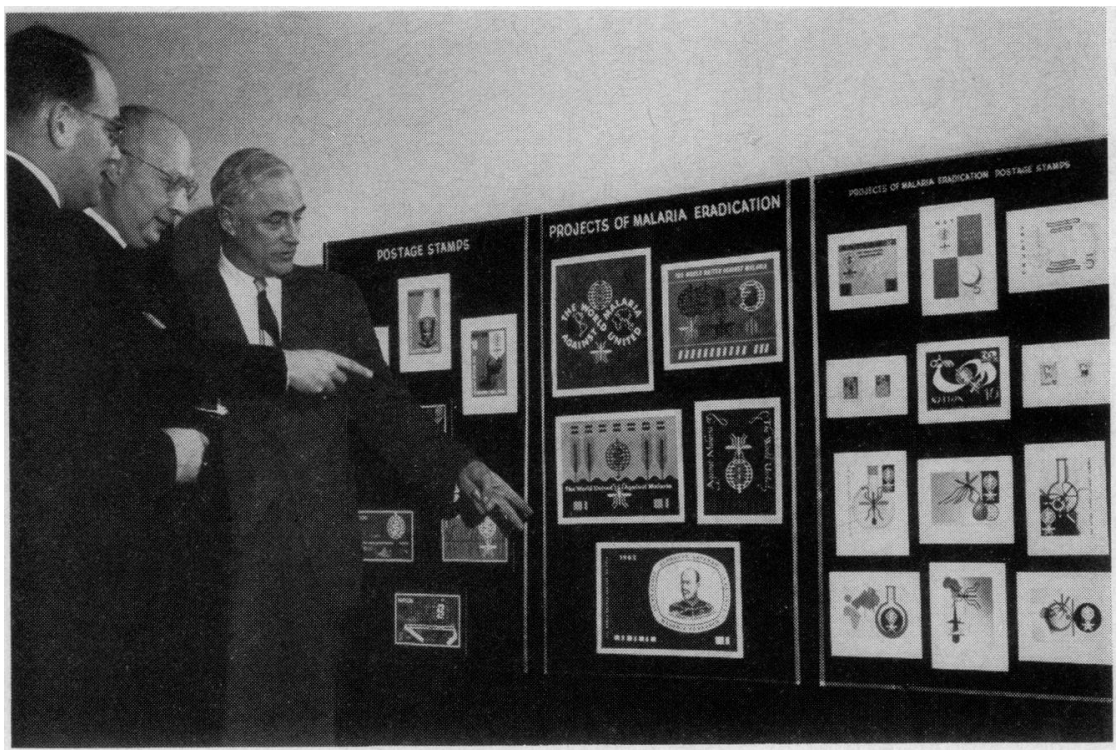

\section{WHO Nations Issue Malaria Stamps}

Postage stamp designs on the theme of malaria eradication are examined by (from left) Manfred R. Lehmann, president of the Intergovernmental Philatelic Corporation; Dr. Rudolph L. Coigney, director of World Health Organization liaison with the United Nations; and J. Stewart Hunter, Assistant to the Surgeon General for Information, Public Health Service, at a press conference held by WHO in New York City on November 17, 1961. Plans were announced for a worldwide postage stamp campaign to publicize malaria eradication efforts.

More than 90 nations are expected to issue malaria eradication stamps during 1962. Most of the stamps will carry the motto, "The World United Against Malaria." Many of the stamp designs will also incorporate the WHO malaria eradication campaign emblem, which consists of a globe symbolizing world unity and an anopheline mosquito being attacked by the Aesculapian staff.

Besides issuing millions of stamps, many governments are further aiding WHO's malaria eradication campaign by donating stamps for philatelic sale. Proceeds will be put into WHO's Malaria Eradication Special Account.

The U.S. stamp on malaria eradication was issued on March 30, 1962 . 